\title{
A safe and convenient synthesis of 4-benzyloxy-3-chloroaniline ${ }^{1}$
}

\author{
Hongfeng Chen," Christopher N. Nilsen, Anusuya Choudhury, and Kirk L. Sorgi \\ Chemical Development, Johnson \& Johnson Pharmaceutical Research \& Development, LLC, \\ 1000 Route 202, Raritan, NJ 08869, USA \\ E-mail: hongfengchen1@gmail.com
}

\begin{abstract}
A convenient, safe, large-scale synthesis of the title compound 4-benzyloxy-3-chloroaniline is described. The commercially available 4-benzyloxy-3-chloronitrobenzene is reduced conveniently using $\mathrm{SnCl}_{2}$ to afford 4-benzyloxy-3-chloroaniline in high yield, high purity, and free of tin residues. This process is suitable for kilogram-scale synthesis of the title compound.
\end{abstract}

Keywords: 4-Benzyloxy-3-chloroaniline, stannous chloride, reduction

\section{Introduction}

4-Benzyloxy-3-chloroaniline has been frequently used as a building block in the construction of potential anti-cancer, ${ }^{2-7}$ anti-diabetes ${ }^{6}$ and anti-viral ${ }^{8}$ agents. Despite the widespread use of this compound, its preparation has not been thoroughly discussed in the literature except for a few limited examples involving small scale (milligrams to grams) preparations. The methods currently reported in the literature include: (1) reduction of 2-chloro-4-nitrophenol to 3-chloro-4hydroxyaniline using $\mathrm{Zn} / \mathrm{NH}_{4} \mathrm{Cl}$ in $\mathrm{MeOH} / \mathrm{H}_{2} \mathrm{O}$, followed by Boc protection of the amine, benzylation of the hydroxy group and deprotection of the Boc group, ${ }^{9}$ (2) reduction of 4benzyloxy-3-chloronitrobenzene by either Raney $\mathrm{Ni}^{10}$ or $\mathrm{Pd} / \mathrm{C}^{4}$ catalyzed hydrogenation, and (3) reduction of 4-benzyloxy-3-chloronitrobenzene mediated by Fe powder in acetic acid ${ }^{8}$ or $\mathrm{NH}_{4} \mathrm{Cl}$ solution. ${ }^{11,12}$ In connection with one of our development projects, we needed quick access to large amounts of this compound.

* Corresponding author. Current Affiliation: Wilmington Pharma Tech Company, 1 Innovation Way, Suite 302, Newark, DE 19711.

Tel.: (302) 737-9916; Fax: (302) 261-7000; e-mail: hongfengchen1@gmail.com. 


\section{Results and Discussion}

Although 4-benzyloxy-3-chloroaniline is commercially available, we quickly found that its purity did not always meet our specifications and could not be used directly. Some commercially available samples were contaminated with 4-amino-2-chlorophenol (4), most likely due to poor control during a hydrogenation step involving 4-benzyloxy-3-chloronitrobenzene (vide infra).

Following a brief survey of the reported procedures, we chose to avoid any large-scale process using hydrogenation conditions involving Raney nickel due to safety concerns associated with its use and the possibility of residual nickel being left in the final product. The reduction of 4-benzyloxy-3-chloronitrobenzene using traditional $\mathrm{Pd} / \mathrm{C}$ catalyzed hydrogenation conditions has been reported for the preparation of 4-benzyloxy-3-chloroaniline but without detailed experimental procedures. ${ }^{4}$ Although this approach was attractive to us, we envisioned that careful control of the reaction conditions would be needed to avoid the possible debenzylation and/or dechlorination.

In order to test this reduction, we reacted 4-benzyloxy-3-chloronitrobenzene in ethanol:THF co-solvents $(1: 1 \mathrm{v} / \mathrm{v})$ with $0.5 \mathrm{~mol} \%$ of $\mathrm{Pd}$ on activated carbon under $20 \mathrm{psi}$ of $\mathrm{H}_{2}$ at ambient temperature. The reaction proceeded rapidly to afford, within $30 \mathrm{~min}$, a reaction mixture containing compounds $\mathbf{2 , 3}$ and $\mathbf{4}$ with compound $\mathbf{4}$ as the major product. Only a trace amount of the desired compound 5 was detected (LC-MS and ${ }^{1} \mathrm{H}$ NMR analyses, Scheme 1).
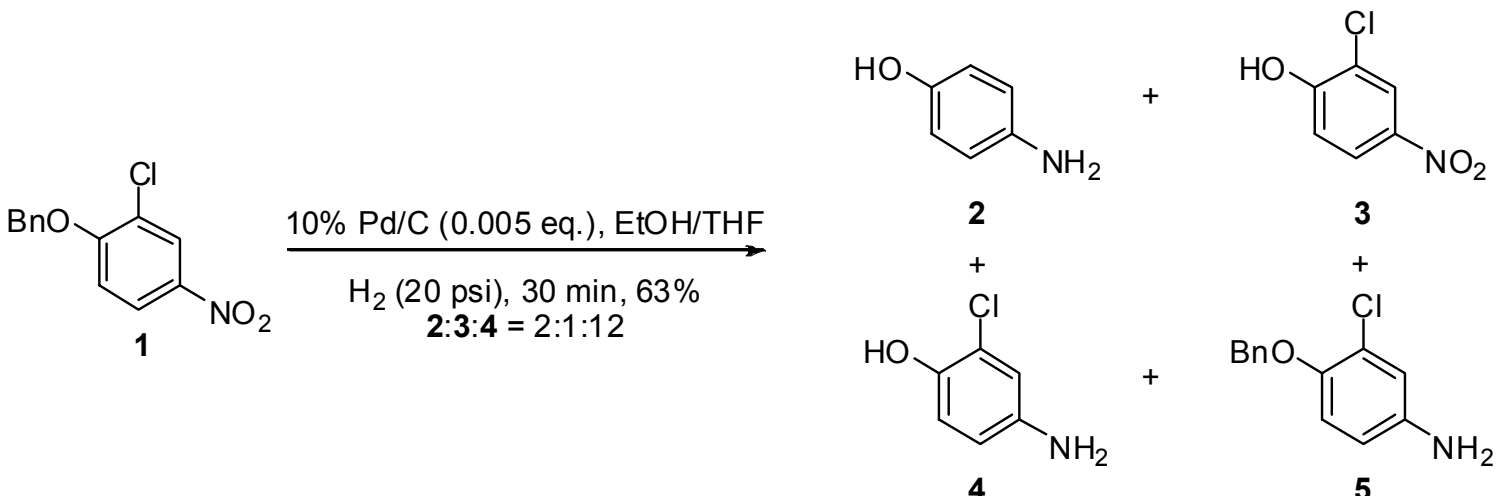

(trace amount)

Scheme 1. Hydrogenation of 4-benzyloxy-3-chloronitrobenzene.

Based on these findings we decided to explore preparing the title compound using nonhydrogenation conditions, starting with the commercially available 4-benzyloxy-3chloronitrobenzene. We required the process to be simple and safe, and amenable for further scale-up. We first tried to reduce 4-benzyloxy-3-chloronitrobenzene in acetic acid with $\mathrm{Fe}$ powder since $\mathrm{Fe}$ powder in acetic acid has been known to reduce the nitro compounds successfully to their corresponding amines. ${ }^{3,8,13}$ As expected, when 4-benzyloxy-3chloronitrobenzene was heated with Fe powder in refluxing acetic acid, the nitrobenzene starting 
material was quickly consumed. However, to our surprise the only product isolated was acetylaniline 6: the acetylation product of the aniline intermediate (Scheme 2). Although we believed that the formation of this by-product could be controlled by adjusting the reaction conditions we chose not to pursue this route further because of the difficulty of removing acetic acid on large scale and the expected exothermic feature of this reaction. ${ }^{13}$

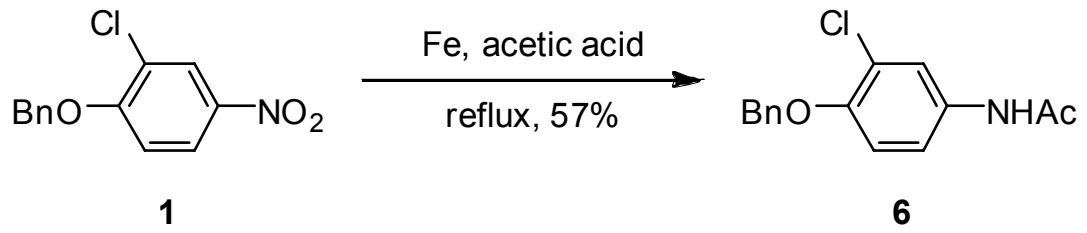

Scheme 2. Reduction of nitrobenzene 1 using Fe in acetic acid.

Reduction of 4-benzyloxy-3-chloronitrobenzene by powdered $\mathrm{Fe}$ in $\mathrm{NH}_{4} \mathrm{Cl}$ solution ${ }^{11,12}$ is also known and could be used for large scale preparation of 4-benzyloxy-3-chloroaniline. However, its workup requires tedious multiple extractions and filtrations. We therefore chose not to pursue this method. Stannous chloride is well known to reduce an aromatic nitro compound to the corresponding aniline under very mild reaction conditions, while a benzyl group and a chlorine functionality is stable under these conditions. ${ }^{14}$ Further more, stannous chloride reduction of aromatic nitro compounds can usually be performed under homogeneous conditions, and we believed that one could precipitate the aniline products as their hydrochlorides directly from the reaction mixture. In fact, Bellamy et. al. ${ }^{14}$ reported the reduction of 4benzyloxynitrobenzene to 4-benzyloxyaniline using stannous chloride under neutral conditions. Under the conditions reported we encountered a thick suspension that made isolation of the product by extraction very difficult. We were glad to find that using acidic conditions afforded a more practical process for the preparation of the title compound. Thus when 4-benzyloxy-3chloronitrobenzene was treated with 4 equivalent of $\mathrm{SnCl}_{2}$ (or $\mathrm{SnCl}_{2} \cdot \mathrm{H}_{2} \mathrm{O}$ ) in acidic aqueous ethanol, the reduction proceeded smoothly and quickly to generate 4-benzyloxy-3-chloroaniline (5) without formation of any detectable debenzylated or dechlorinated side-products. Within one and a half hours, HPLC analysis and TLC analysis indicated that the starting material was completely consumed. Water was then added to the reaction mixture and the aniline hydrochloride precipitated as an easily filterable off-white solid. The solid was collected by simple filtration and washed with water to remove soluble inorganic salts. The wet cake was dried to afford the hydrochloride of the title compound in nearly quantitative yield.

To prepare the free base form of the title compound, the solid was treated with a $2 \mathrm{~N} \mathrm{NaOH}$ solution and extracted with dichloromethane or ethyl acetate. Alternatively, the wet cake was treated without drying with a $2 \mathrm{~N} \mathrm{NaOH}$ solution to $\mathrm{pH} 12$, and the mixture extracted with dichloromethane or ethyl acetate, washed with brine, dried $\left(\mathrm{Na}_{2} \mathrm{SO}_{4}\right)$, filtered and concentrated to afford the free base form of 4-benzyloxy-3-chloroaniline as an off-white solid. The purity of the product prepared in this method was satisfactory for our use ( $>99 \%$ by HPLC area analysis), and 
the amount of residual Sn in the material was at the level of $1 \mathrm{ppm}$ (Scheme 3$).{ }^{15}$ If desired, the material can be further purified by recrystallization in ethyl acetate/heptane to generate 4benzyloxy-3-chloroaniline as an off-white crystalline solid free of any tin residues.

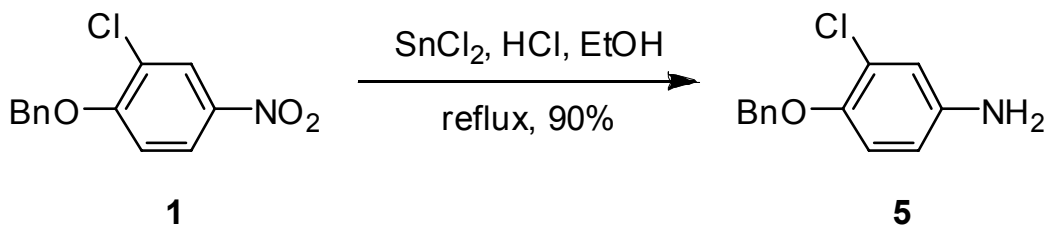

Scheme 3. Stannous chloride reduction of 4-benzyloxy-3-chloronitrobenzene.

In summary, we have reported here that $\mathrm{SnCl}_{2}$ effectively reduced 4-benzyloxy-3chloronitrobenzene to form 4-benzyloxy-3-chloroaniline in excellent yield without cleaving either the benzyl group or the chlorine group. The process is simple, safe and can be easily scaled-up to provide larger amount of material in excellent purity and yield.

\section{Experimental Section}

4-Benzyloxy-3-chloroaniline (5). In a 5 L, 3-necked round bottom flask equipped with an overhead stirrer, a thermal couple and a water-cooled reflux condenser was added tin(II) chloride dihydrate $(427.8 \mathrm{~g}, 1.90 \mathrm{~mol})$, ethanol $(1250 \mathrm{~mL})$ and concentrated $\mathrm{HCl}(250 \mathrm{~mL})$. The mixture was stirred and heated to $70{ }^{\circ} \mathrm{C}$ to become a clear solution. To this hot solution was added portion-wise 3-chloro-4-benzyloxynitrobenzene (129.0 g, $0.48 \mathrm{~mol}, 5$ portions over $30 \mathrm{~min}$ ). The solution was kept slightly refluxing during the addition. After the addition, the mixture was heated for 1.5 hours at which time TLC and HPLC analysis indicated that no starting material remained. Water $(1250 \mathrm{~mL})^{15}$ was added and the resulting solution was allowed to cool to room temperature. The product precipitated as a white solid during cooling. The mixture was further cooled and stirred for $30 \mathrm{~min}$ at $15^{\circ} \mathrm{C}$ and the precipitation was collected by vacuum filtration through a Medium-sintered glass funnel, washed with water $(2 \times 250 \mathrm{~mL}$ then $500 \mathrm{~mL})$, suction dried thoroughly and further dried in a vacuum oven at $50{ }^{\circ} \mathrm{C}$ under house vacuum until constant weight to afford 4-benzyloxy-3-chloroaniline hydrochloride as an off-white powder (131.1g, 99\%). Mp (by DSC): $224.4^{\circ} \mathrm{C}$.

For the preparation of the free base form of 4-benzyloxy-3-chloroaniline, the drying step is not necessary. The wet solid was transferred to a $1 \mathrm{~L} 3$-necked round bottom flask equipped with an overhead stirrer and dichloromethane $(200 \mathrm{~mL})$ was added. The suspension was cooled with an ice-water bath. $\mathrm{NaOH}$ solution $(2 \mathrm{~N})$ was added with stirring to adjust the solution to $\mathrm{pH} \sim 12$ (300 $\mathrm{mL}$ of $\mathrm{NaOH}$ solution added). The mixture was transferred to a separatory funnel and the organic phase was separated. The aqueous phase was extracted with dichloromethane $(2 \times 200$ $\mathrm{mL})$. The combined organic phase was washed with brine $(100 \mathrm{~mL})$ and dried $\left(\mathrm{MgSO}_{4}\right)$, filtered 
and concentrated in vacuo to afford the product as an off-white solid $(90.0 \mathrm{~g}, 79 \%) .{ }^{1} \mathrm{H}$ NMR $\left(300 \mathrm{MHz}, \mathrm{CDCl}_{3}\right) \delta$ 7.45-7.43 (m, $\left.2 \mathrm{H}\right), 7.39-7.29$ (m, $\left.3 \mathrm{H}\right), 6.78(\mathrm{~d}, \mathrm{~J}=8.6 \mathrm{~Hz}, 1 \mathrm{H}), 6.74(\mathrm{~d}, \mathrm{~J}$ $=2.8 \mathrm{~Hz}, 1 \mathrm{H}), 6.48(\mathrm{dd}, \mathrm{J}=2.8,8.6 \mathrm{~Hz}, 1 \mathrm{H}), 5.03(\mathrm{~s}, 2 \mathrm{H}), 3.46(\mathrm{bs}, 2 \mathrm{H}) ;{ }^{13} \mathrm{C} \mathrm{NMR}(75.47$ $\left.\mathrm{MHz}_{,} \mathrm{CDCl}_{3}\right) \delta 147.2,141.4,137.2,128.5,127.9,127.4,124.6,117.18,117.15,114.2,72.4 ; \mathrm{mp}$ (by DSC): $58.4{ }^{\circ} \mathrm{C}$; Anal. Calcd for $\mathrm{C}_{13} \mathrm{H}_{12} \mathrm{ClNO}$ : C 66.81, H 5.18, Cl 15.17, N 5.99. Found: C 67.01, H 5.21, Cl 15.13, N 5.93, Sn $<1$ ppm; MS (EI) m/z calcd for $\mathrm{C}_{13} \mathrm{H}_{13} \mathrm{ClNO}(\mathrm{MH}+)$ 234, found 234.

$\boldsymbol{N}$-(4-(Benzyloxy)-3-chlorophenyl)acetamide (6). To a dry 3-necked round bottom flask equipped with an overhead stirrer, a thermal couple and a water-cooled reflux condenser was added Fe (325 mesh, Aldrich, $13.24 \mathrm{~g}, 0.237 \mathrm{~mol}, 2.50 \mathrm{eq})$ and glacial acetic acid (100 mL). The mixture was heated to $50{ }^{\circ} \mathrm{C}$. 4-Benzyloxy-3-chloronitrobenzene (1, $\left.25.0 \mathrm{~g}, 94.8 \mathrm{mmol}\right)$ was added to the hot suspension portion-wise in 1 hour, maintaining the reaction mixture to $80-85^{\circ} \mathrm{C}$. After the addition finished the mixture was heated to reflux $\left(119.5{ }^{\circ} \mathrm{C}\right)$. The reaction was monitored by TLC analysis $\left(\mathrm{SiO}_{2}\right.$, EtOAc, $\left.\mathrm{R}_{\mathrm{f}}(\mathbf{1})=0.9, \mathrm{R}_{\mathrm{f}}(\mathbf{6})=0.5\right)$. When the reaction was complete ( 90 minutes), the reaction mixture was cooled to $\mathrm{rt}$ and filtered through a celite pad to remove the black solid. The filter cake was rinsed with glacial acetic acid $(100 \mathrm{~mL})$ and the combined filtrate was concentrated in rotary evaporator to get a dark solid. This solid was dissolved in sat. $\mathrm{Na}_{2} \mathrm{CO}_{3}$ solution until the $\mathrm{pH}$ value of the aqueous phase reached 12 . The mixture was then extracted with EtOAc $(3 \times 250 \mathrm{~mL})$. The combined extract was washed with brine $(100 \mathrm{~mL})$, dried $\left(\mathrm{MgSO}_{4}\right)$, filtered and concentrated in rotavap to afford an off-white solid. This solid was further dried in an oven under house vacuum at $50{ }^{\circ} \mathrm{C}$ until constant weight to afford compound 6 as an off-white solid (15.00g, 57\%). ${ }^{1} \mathrm{H}$ NMR $\left(300 \mathrm{MHz}, \mathrm{CDCl}_{3}\right) \delta 7.55$ (d, $J=2.4 \mathrm{~Hz}, 1 \mathrm{H}), 7.46-7.26$ (m, $6 \mathrm{H}), 7.20$ (bs, $1 \mathrm{H}), 6.89$ (d, $J=8.9 \mathrm{~Hz}, 1 \mathrm{H}), 5.12$ (s, $2 \mathrm{H}), 2.14$ $(\mathrm{s}, 3 \mathrm{H}) ;{ }^{13} \mathrm{C} \mathrm{NMR}\left(75.47 \mathrm{MHz}, \mathrm{CDCl}_{3}\right) \delta 168.2,151.1,136.5,131.9,128.6,128.0,127.1,123.6$, 122.6, 119.6, 114.7, 71.3, 24.3; mp (by DSC) $140.2{ }^{\circ} \mathrm{C}$; MS (EI) m/z calcd for $\mathrm{C}_{15} \mathrm{H}_{15} \mathrm{ClNO}_{2}$ (MH+) 276, found 276.

\section{Acknowledgements}

We thank Dr. Xun Li and Mr. Scott Youells for helpful discussions. 


\section{References and Notes}

1. Caution! 4-Benzyloxy-3-chloroaniline is known to be mutagenic. Handling of this compound requires proper use of personal protective equipments (PPE).

2. Xu, G.; Lee, L.; Connolly, P. J.; Middleton, S. A.; Emanuel, S. L.; Hughes, T. V.; Abad, M. C.; Karnachi, P. S.; Wetter, S. K. WO 2007081630, 2007.

3. Zhang, C.; Dumas, J.; Zhu, Q.; Smith, R.; Liu, Q.; Verma, S.; Duquette, J.; Zhao, Q.; Fan, D.; Bondar, G.; Coish, P. WO 2006023843, 2006.

4. Petrov, K. G.; Zhang, Y.-M.; Carter, M.; Cockerill, G. S.; Dickerson, S.; Gauthier, C. A.; Guo, Y.; Mook, R. A.; Rusnak, D. W.; Walker, A. L.; Wood, E. R.; Lackey, K. E. Bioorg. Med. Chem. Lett. 2006, 16, 4686.

5. Long, Y.; Jin, Y.; Ding, J.; Lin, L. CN 1858040, 2006.

6. Jung, D. K.; Alberti, M. J. WO 2006086539, 2006.

7. Cockerill, G. S.; Lackey, K. E. WO 2001004111, 2001.

8. Boyd, V. A.; Cameron, D. R.; Jia, Q.; Sgarbi, P. W. M.; Wacowich-Sgarbi, S. A. WO $2007002639,2007$.

9. Jin, Y.; Zhou, Z.-Y.; Tian, W.; Yu, Q.; Long, Y.-Q. Bioorg. Med. Chem. Lett. 2006, 16, 5864.

10. Capps, D. B.; Dunbar, J.; Kesten, S. R.; Shillis, J.; Werbel, L. M. J. Med. Chem. 1992, 35, 4770.

11. Wissner, A.; Rabindran, S. K.; Tsou, H.-R. US 2005059678, 2005.

12. Wissner, A.; Rabindran, S. K.; Tsou, H.-R. WO 2005034955, 2005.

13. Grimm, J.; Liu, F.; Stefanick, S.; Sorgi, K. L.; Maryanoff, C. A. Org. Process Res. Dev. 2003, 7, 1067.

14. Bellamy, F. D.; Ou, K. Tetrahedron Lett. 1984, 25, 839.

15. The amount of water added is critical for controlling the residual tin in the final product. If too much water is added the Sn (IV) species are hydrolyzed to form a milky supernatant that contaminates the precipitated aniline hydrochloride. The $\mathrm{Sn}$ contamination in the hydrochloride cannot be totally removed in the free base formation step. This resulted in several occasions that the residual $\mathrm{Sn}$ in the isolated free base to be $>50 \mathrm{ppm}$. To avoid the hydrolysis of the $\mathrm{Sn}(\mathrm{IV})$ species, which is a side product from the oxidation of $\mathrm{SnCl}_{2}$, we found that the amount of water added should be no more than the original amount of ethanol used. With control of the amount of water added to the reaction mixture the residual tin in the isolated aniline free base is at the level of $1 \mathrm{ppm}$. 